


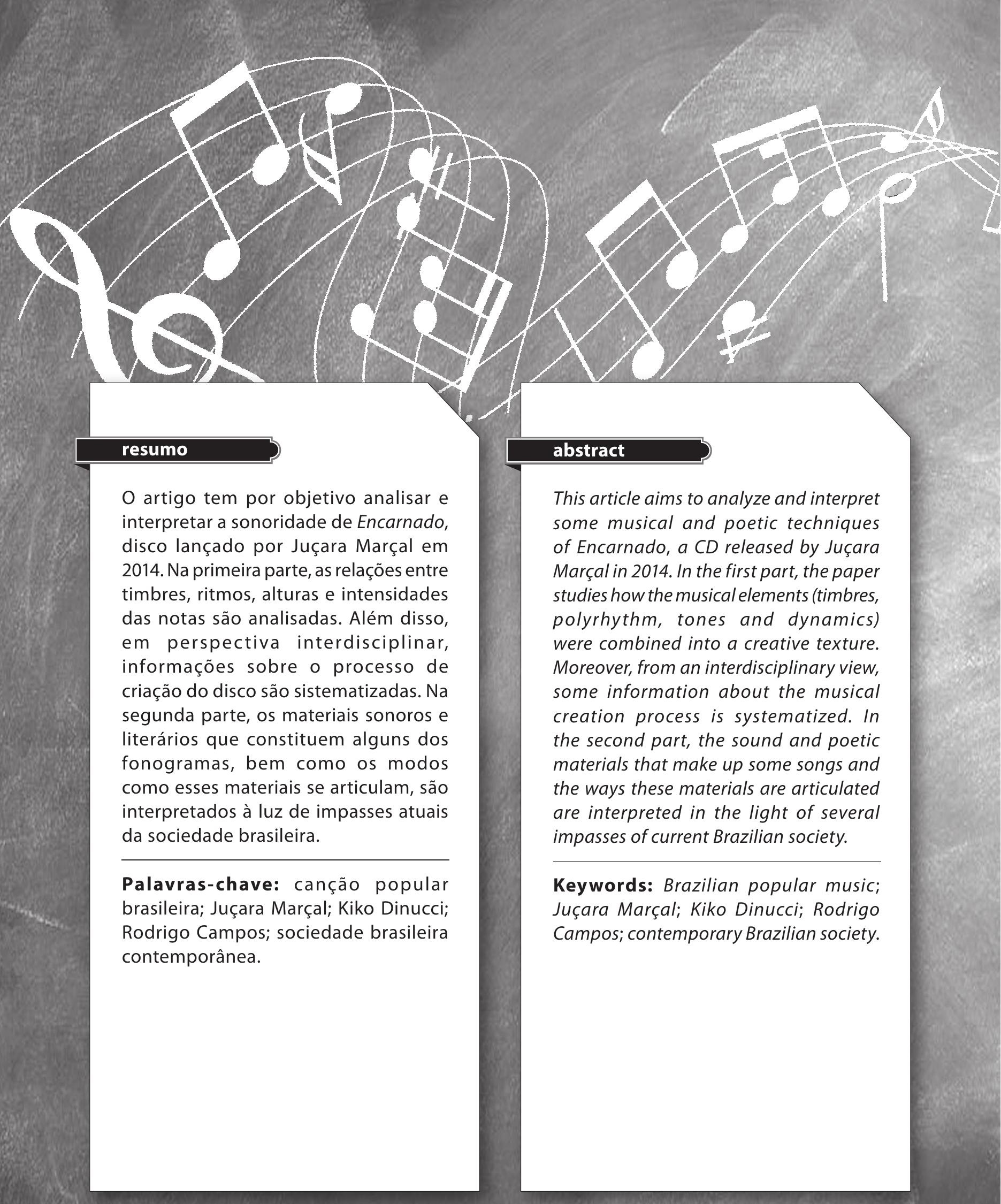




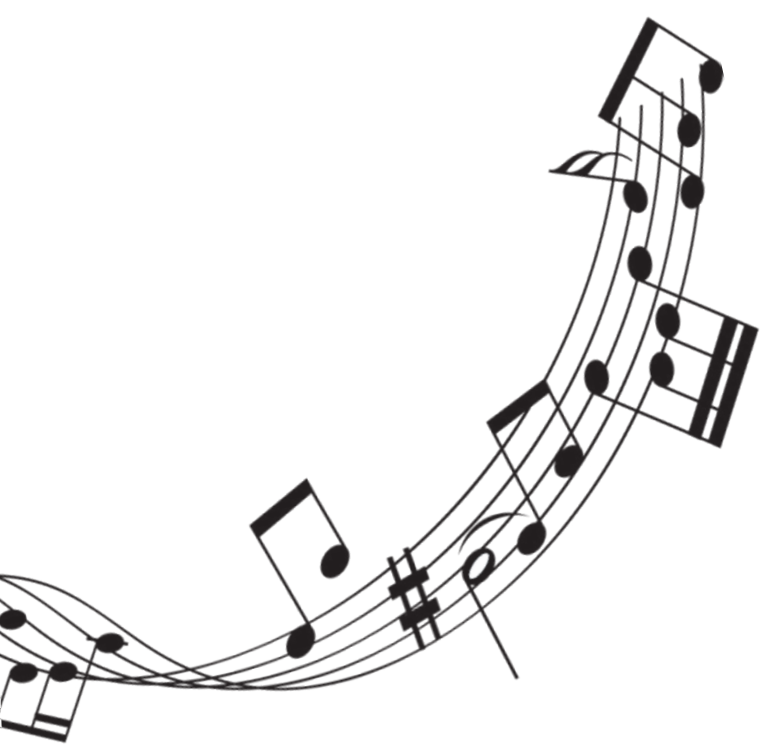

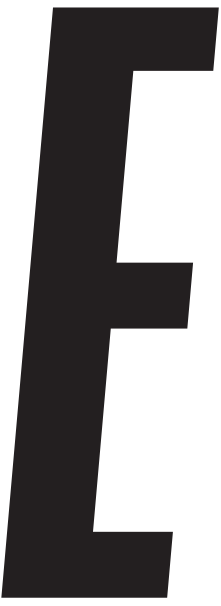

ncarnado se estrutura com uma mesma sonoridade desde a primeira faixa, "Velho Amarelo" (Rodrigo Campos), até a penúltima, "Presente de Casamento" (Thiago França e Romulo Fróes) ${ }^{1}$. Como não se trata da reprodução de um clichê de mercado, essa característica não é diretamente explicada pelos processos de estandardização, ou seja, a sua coerência radical expressa e pressupõe certa lógica que, em sua originalidade, pede reflexão. Em outras palavras, a escuta do disco mobiliza a sensibilidade e os afetos, e não há por que estranhar quando se afirma que o efeito imediato é a tensão que se sente na pele (Fagundes, 2016). Mas o disco também convoca o ouvinte, tenha conhecimento ou não da linguagem musical, a pensar sobre significados que se colocam concretamente desde a matéria sonora. De resto, não custa lembrar que "não há sentimentos 'puros', sensações 'puras' ou 'puras' ideias" e também que uma das tarefas da crítica é a de avaliar uma obra recente buscando reconhecer as especificidades e a amplitude do conhecimento artístico que ela proporciona, isto é, buscando elucidar de que forma a obra (re)cria situações, ações, discursos e conflitos contemporâneos e nos

1 Juçara Marçal, Encarnado, Independente, 2014. Disponível em: http://www.jucaramarcal.com/\#!downloads/ cfn3. Acesso em: 26/jul./2016. faz experimentá-los no plano simbólico (Konder, 2013, pp. 99, 22-23; Engels, 2010).

\section{ESTUDANDO A SONORIDADE}

Esquematizando, o que sempre implica deixar de lado particularidades mais ou menos importantes, diga-se que a sonoridade dessas 11 faixas de Encarnado é composta pela interação de quatro relações. A primeira delas é a combinação dos timbres da voz de Juçara Marçal, uma gama que inclui do aveludado ao ríspido, e dos diversos timbres ruidosos das guitarras de Kiko Dinucci e de Rodrigo Campos - em duas faixas, "Velho Amarelo" e "Ciranda do Aborto" (Kiko Dinucci), em vez de guitarra, Rodrigo toca cavaquinho. O timbre áspero da rabeca de Thomas Rohrer se mistura a partir da quarta faixa, "Pena Mais que Perfeita" (Gui Amabis e Regis Damasceno), permanecendo até a oitava, "E o Quico?" (Itamar Assumpção). Túlio Villaça observou, na sua análise de "Ciranda do Aborto", que uma "delicada costura é feita do arame farpado de timbres distorcidos", o que resulta em boa parte dos "efeitos de pedais e estúdio como

Esteartigoé dedicadoà recordação de Joaquim Alves de Aguiar.

WALTER GARCIA é professor do Instituto de Estudos Brasileiros da Universidade de São Paulo, compositor, violonista e autor de Melancolias, Mercadorias (Ateliê). 
o overdrive", e concluiu com a imagem de que os instrumentos "são navalhas e bisturis cortando o ouvido" (Villaça, 2014). Essa imagem, brutal e certeira, poderia ser generalizada para as 11 faixas. Acrescento outra: os instrumentos soam agressivos como pedaços de metais e de tijolos, lascas de plástico duro, estilhaços de vidro, pedras; mas esses escombros se ajustam perfeitamente, construindo ambientes nos quais a voz segue fluida, solta, por vezes se chocando, todavia, com as arestas que ostentam um forte aspecto ruinoso.

Antes de prosseguir com a análise, registrarei alguns dados do processo de criação do disco. De acordo com Juçara Marçal, o diálogo das guitarras de Kiko Dinucci e Rodrigo Campos, entre si e com o canto, chamou-lhe a atenção no trabalho do Passo Torto, coletivo formado por Kiko, Rodrigo, Marcelo Cabral e Romulo Fróes². E também durante os ensaios para dois shows: Tradição, $e$ o Samba Continua..., com repertório de Geraldo Filme, apresentado em 31 de agosto, $1^{\circ}$ e 2 de setembro de 2012, no Sesc Vila Mariana, em São Paulo; e Plínio Marcos em Prosa e Samba, apresentado em 27 de março de 2013, no Sesc Pompeia, também em São Paulo. Em ambos os trabalhos, antes dos ensaios com todos os músicos, Kiko Dinucci e Rodrigo Campos delineavam os arranjos ensaiando com Juçara $\mathrm{Marçal}^{3}$.

O que viria a ser Encarnado teve início efetivo em 5 de abril de 2013. Ainda segundo Juçara Marçal, os ensaios desse projeto, então chamado "Estudando o Passo Torto", passaram a ocorrer "bem esporadicamente", e a partir dos meses de junho e julho daquele ano se intensificaram ${ }^{4}$. Hou-

2 Passo Torto, Passo Elétrico, YB Music, 2013. Disponível em:

http://www.passotorto.com.br/site/Downloads.html. Acesso em: 5/ago./2016.

3 Entrevista que realizei com Juçara Marçal em 2 de agosto de 2016. Esclareça-se que ela participou somente da apresentação de Plínio Marcos em Prosa e Samba. Notar os vínculos afetivos e artísticos implicados no processo; também notar o desperdício de material que decorre da praxe do Sesc, ao patrocinar projetos musicais e programar tão poucas apresentações; e, por fim, notar como toda essa dinâmica reproduz, guardadas as devidas proporções, o trabalho com música popular brasileira nas principais emissoras de rádio dos anos 1940 e 1950.

4 Entrevista que realizei com Juçara Marçal em 2 de agosto de 2016. ve duas apresentações na Casa de Francisca, em São Paulo, em 10 e 11 de outubro de 2013, já com a participação de Thomas Rohrer e com repertório e arranjos definidos ${ }^{5}$. As gravações do disco foram realizadas em 18, 19 e 20 de novembro de 2013, por Fernando Sanches, no Estúdio El Rocha ${ }^{6}$.

A segunda das quatro relações que estruturam a sonoridade de Encarnado é o jogo rítmico entre a voz, as guitarras (ou a guitarra e o cavaquinho) e a rabeca; além de, em três faixas, atuar ou o sax tenor ou o pocket piano de Thiago França ou a kalimba (a rigor, único instrumento de percussão) de Juçara Marçal. O jogo rítmico se estabelece com balanço, ainda que não atinja o corpo, levando-o a dançar. E, de modo geral, dá sustentação à mistura de timbres: enquanto a voz é envolvida pelos instrumentos que soam como se quisessem rasgar a audição, a polirritmia vai traçando linhas e, com elas, vai estabelecendo espaços. As faixas se baseiam em diferentes padrões rítmicos. Entretanto, uma vez que esses padrões nem estão marcados de forma explícita, nem são executados por instrumentos que se consagraram na cristalização dos vários ritmos no mercado hegemôni-

5 Assisti à apresentação de 10 de outubro de 2013, assim como ao show de lançamento, que contou com a participação de Thiago França, em 15 de abril de 2014, no Sesc Vila Mariana.

6 Encarnado também foi mixado e masterizado por Fernando Sanches no Estúdio El Rocha, em São Paulo. Para os(as) cancionistas, informações sobre os instrumentos e os pedais serão bastante úteis. Kiko Dinucci: "Usei uma guitarra Fender Stratocaster ano 2000, um amplificador Bassman da Fender. Pedais 70's da Fulltone (silicone), esse foi o fuzz que eu mais usei. [Pedal] Fuzz Face. Um outro fuzz bem barulhento da Zvex chamado Fuzz Factory (germanium), um overdrive chamado Sparkle Drive e um delay chamado Memory Man. Mas a maioria do disco foi gravada com o 70's". Entrevista que realizei com Kiko Dinucci em 29 de julho de 2016. Rodrigo Campos tocou uma guitarra Fender Jazzmaster Blacktop mexicana e um cavaquinho Manoel Andrade de 2006 . O cavaquinho foi gravado "por duas vias, direto no microfone e também mandando para o amplificador, passando por pedais, um Fuzz Fulltone 69, um reverb Space Echo e um chorus, o da Nano da Electro Harmonix. Usei esses pedais na guitarra também. Além do Memory Boy, um delay com modulação da Electro Harmonix e uma distorção da Zvex, o Box of Rock". Entrevista que realizei com Rodrigo Campos em 3 de agosto de 2016. Thomas Rohrer gravou "com uma rabeca do Seu Nelson da Rabeca", sem pedais, com "captação em dois canais: um microfone condensador mais um amplificador microfonado". Entrevista que realizei com Thomas Rohrer em 5 de agosto de 2016. 
co, a sonoridade desloca a escuta, impedindo que os gêneros ou que os rótulos comerciais (samba, ciranda, reggae, frevo, etc.), com seus respectivos conjuntos de valores, significados, práticas e expectativas (Williams, 2011, pp. 43-68; Fabbri, 1981), se anteponham imediatamente às particularidades dos fonogramas.

A terceira das quatro relações que estruturam a sonoridade de Encarnado já está indicada e decorre da escolha dos instrumentos. Ainda que não tenha sido feita de modo intencional (segundo Juçara Marçal, de fato, não houve essa intenção) ${ }^{7}$, a escolha de não incluir instrumentos de percussão, ou mesmo baixo elétrico, resultou numa tessitura (no plano das alturas, espectro de notas que abrange da mais aguda à mais grave) bastante adequada ao formato MP3 (320 kbps). Duas considerações merecem ser feitas. A primeira é que trabalhar com uma instrumentação indispensável não é, evidentemente, a única solução para quem, não dispondo de muito dinheiro para produzir um disco, dispõe de tempo para tocar junto, seja pela afinidade artística e pela confiança na qualidade do trabalho, seja pela camaradagem ou pela amizade, seja por tudo isso. O que importa ressaltar é que a instrumentação essencial, que não se guia diretamente por modelos do mercado hegemônico, responde às condições de produção de Encarnado sem mascará-las. A segunda consideração é que, embora adequada ao formato MP3 (uma vez que não há frequências graves que se perderiam na compressão do áudio, sem falar na reprodução em computadores ou em celulares e na interferência de fones de ouvido), o fato é que a sonoridade do disco se ajusta às atuais condições de difusão e de audição, mas, espero que já esteja claro, propõe novos parâmetros de escuta.

A interação do plano das durações, em que há polirritmia, e do plano das alturas das notas resultou daquele processo de criação registrado acima. Ampliarei agora o registro. Segundo Rodrigo Campos, "o processo da turma é sempre desconstruir as harmonias originais. Então, as canções do Passo Torto, como as do Encarnado, ficam despidas das harmonias em que foram compostas. As harmonias ficam servindo mais como um guia na feitura dos arranjos"s.

Abordarei a questão me limitando à análise dos compassos iniciais de "Ciranda do Aborto". Apresentei a Kiko Dinucci duas hipóteses acerca da primeira frase da sua guitarra: a) conscientemente ou não, ele havia utilizado uma escala com as notas mi, fá\#, sol, lá\#, si, dó, ré (I, II, bIII, \#IV, V, bVI, bVII; o sétimo grau é tocado depois por Rodrigo Campos, sobre essa mesma frase de Kiko Dinucci); b) conscientemente ou não, ele havia fraseado em cima do encadeamento harmônico observável na Figura 1. Kiko Dinucci respondeu:

"Os improvisos partiram de acordes naturais. Muitas vezes não sabíamos nem qual era a sequência de acordes, nos guiávamos somente pelo tom. No caso da 'Ciranda do Aborto', eu passei a sequência de acordes naturais para o Rodrigo, e criamos riffs em cima de cada um desses acordes. Os intervalos estranhos vieram para estragar, deslocar o acorde do lugar-comum, como pequenas dissonâncias para envenenar o acorde natural. No disco inteiro, essas escalas estranhas dos riffs surgiram quase como brincadeira, para entortar mesmo, tirar o

\section{FIGURA 1}

Frase inicial da guitarra de Kiko Dinucci em "Ciranda do Aborto"

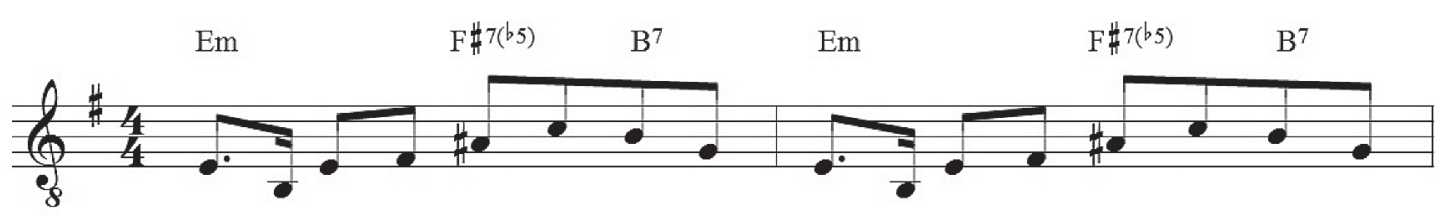

7 Entrevista que realizei com Juçara Marçal em 2 de agosto de 2016.
8 Entrevista que realizei com Rodrigo Campos em 3 de agosto de 2016. 
chão. Essa experiência se radicalizou mais ainda no terceiro disco do Passo Torto, em parceria com a Ná Ozzetti. Nesse disco, somente o violão do Romulo [Fróes] toca no mesmo tom da Ná, as guitarras e o baixo fazem os intervalos mais absurdos. Mas em nenhum momento a gente pensa ou calcula esses intervalos. A gente vai jogando, sem pensar muito na escala ou no tom, até as coisas se encaixarem, mesmo que pareça uma trama estranha de melodias em contraponto. No disco da Elza Soares [A Mulher do Fim do Mundo], tem essas tramas de guitarras, mas pegamos mais leve" .

Observemos agora a relação entre a guitarra e a voz no início de "Ciranda do Aborto". Enquanto Kiko Dinucci toca a nota lá\#, Juçara Marçal canta a nota lá (Figura 2).

É evidente que o intervalo de meio-tom, entre lá e lá\#, entortou o lugar-comum (lembrar que a guitarra soa uma oitava abaixo). Porém, o choque não parece forçado. Quando se escuta a dissonância, ela está encaixada, o que não significa que a análise musical não possa contribuir para elucidar a percepção. Deixando de lado as duas hipóteses que apresentei, e sem levar em conta a performance de Juçara Marçal, a qual não acentua o choque, uma explicação para o encaixe está no fato de que a nota lá\#, tocada pela guitarra nos primeiros compassos, antecipa o final da parte A, quando duas tensões confluem: a) a última nota cantada é justamente lá\# ("Pra ele não acordar"), bastante tensa porque não se inclui na escala de Mi menor (um bom exercício é cantar a nota lá e reparar como o efeito de tensão diminui); b) essa nota lá\# é cantada sobre o arpejo de F\#7 feito pelo cavaquinho (notas fá\#, lá\#, dó\#, mi); e o dominante secundário (trítono lá\# - mi) não é sucedido pelo acorde de dominante (não se vai para B7, trítono lá - ré\#). Assim, a dissonância dos primeiros compassos se justifica no todo da audição, o que a análise musical ajuda a compreender.

Ainda segundo Kiko Dinucci, além de ter sido colocada em prática no Passo Torto e nos shows Tradição, e o Samba Continua... e Plínio Marcos em Prosa e Samba, essa concepção de arranjo já estava presente desde o primeiro disco do Metá Metá (trio formado por ele, Thiago França e Juçara Marçal), gravado em 2010, e havia surgido também de uma necessidade rítmica: "Como não tinha a percussão, a saída era ficar contrapondo violão e sax". Ao mesmo tempo, não deixava de ser o desdobramento da "visão horizontal do violão" ou da "estrutura melódica da harmonia" em Itamar Assumpção e em Tom Zé; bem como não deixava de ser o desdobramento do violão de Kiko Dinucci em "Imitação" (Batatinha), samba gravado por ele e Juçara Marçal no disco Padê, em $2006^{10}$.

\section{FIGURA 2}

\section{Relação entre a guitarra e a voz no início de "Ciranda do Aborto"}

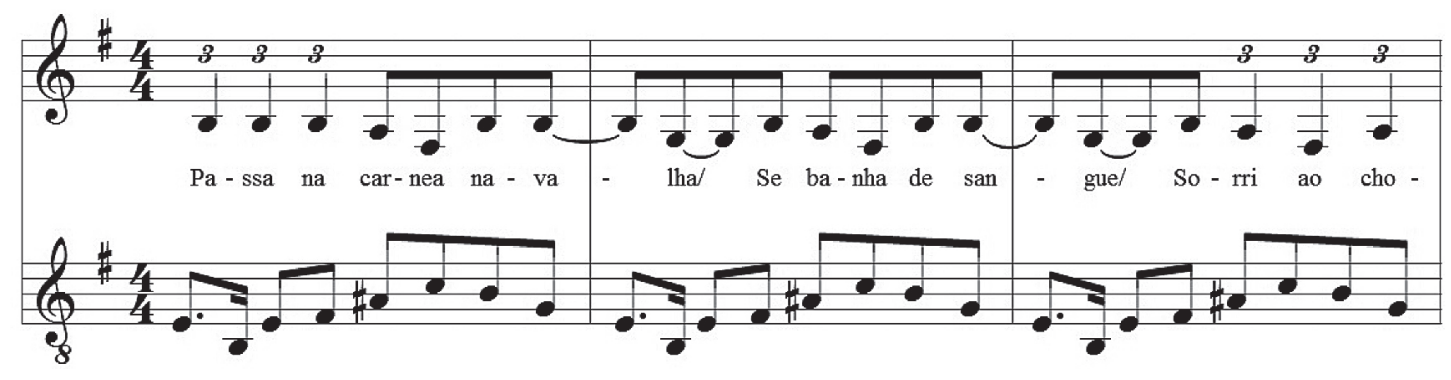

9 Entrevista que realizei com Kiko Dinucci em 3 de agosto de 2016. Passo Torto e Ná Ozzetti, Thiago França, YB Music, 2013. Disponívelem:http://www.passotorto.com.br/site/Downloads.html. Acesso em: 5/ago./2016. Elza Soares, A Mulher do Fim do Mundo, Circus/Natura Musical, 2015. Disponível em: http://www.naturamusical.com.br/ouca-mulher-do-fim-do-mundo-novo-disco-da-elza-soares. Acessoem:5/ago./2016
10 Entrevista que realizei com Kiko Dinucci em 8 de junho de 2014. Metá Metá, Metá Metá, Desmonta/ Circus, 2011 [ano de lançamento do disco]. Disponível em: http://www.jucaramarcal.com/\#!downloads/ cfn3. Acesso em: 26/jul./2016. Juçara Marçal e Kiko Dinucci, Padê, Cooperativa de Música, 2007 [ano de lançamento do disco]. 
A quarta e última relação diz respeito às intensidades (na linguagem coloquial, ao volume) de voz e instrumentos em Encarnado. Em interação com as outras três relações, a de timbres, a de durações (polirritmia) e a de alturas, a relação das intensidades constrói o efeito de submersão da voz no ambiente sonoro ruinoso. Isso ocorre, é claro, como resultado da manipulação do som. Destacarei apenas dois eventos: a) os instrumentos não foram colocados atrás, e sim ao lado da voz, ainda que não se perca nunca a sensação elementar provocada por uma canção popular-comercial desde que ela seja produzida, veiculada e ouvida de forma eficiente: a de que escutamos "alguém dizendo alguma coisa de uma certa maneira" (Tatit, 1986, p. 6); b) o compressor atuou de modo decisivo na matéria da voz; isso se torna mais perceptível na décima primeira faixa, "Presente de Casamento", a partir de 1:00, quando as guitarras silenciam e a voz segue, a cappella, por mais 17 segundos.

\section{OS SENTIDOS DE ENCARNADO}

Quais sentidos podem ser extraídos dessa sonoridade, da qual procurei apresentar a estrutura geral e alguns traços essenciais? Encarnado mantém uma grande violência represada e nos faz experimentá-la. O canto de Juçara Marçal permanece ríspido em "Damião" (Douglas Germano e Everaldo Ferreira da Silva) e em todas as execuções da parte A de "Queimando a Língua" (Romulo Fróes e Alice Coutinho); expressa desespero na parte C de "Ciranda do Aborto"; e se mantém tensionado durante "Presente de Casamento", quando explora a passagem entre a voz de cabeça e a voz de peito (colocando-se, portanto, em um registro tradicionalmente evitado) ${ }^{11}$. Todavia, o canto não explode, mantendo-se de algum modo controlado. Explode, sim, gritando em "Não Tenha Ódio no Verão" (Tom Zé). Porém, nessa mesma faixa, logo depois de gritar, o canto retoma o seu aparente controle, tão mais aparente quanto irônica é a sua intenção.

11 Entrevista que realizei com Juçara Marçal em 2 de agosto de 2016.
Ao mesmo tempo, a violência se avoluma e se mantém represada nos próprios instrumentos, os quais também parecem prontos para arrebentar a sonoridade que constroem, mas só a arrebentam de vez no final da "Ciranda do Aborto", um "final caótico, que traduz musicalmente o horror do assunto tratado na canção" (Fróes, 2014).

O grande tema cantado em Encarnado é o da morte, conforme Romulo Fróes assinala no texto de apresentação do disco. Aparecendo "de muitas maneiras" no repertório, o tema "parece indicar uma busca por renovação, renascimento, um desejo por um 'outro corpo', uma 'nova carne'" (Fróes, 2014). A síntese talvez seja a décima faixa, "A Velha da Capa Preta" (Siba Veloso). Estilizando a cultura de tradição oral, a composição narra que "o povo" hoje está se matando, tomando o emprego da entidade que imaginariamente sempre agiu sem vínculos sociais e políticos, apenas conforme as leis da natureza. A canção fora gravada por Siba em clima carnavalesco - afinal, tratava-se de um frevo ${ }^{12}$. Escutada agora em clima de programa televisivo, em chave agressiva e irônica, "A Velha da Capa Preta" nos dá um conselho nada festivo, nada melancólico: "Só a força resolve onde impera a força/ E onde há humanos só os humanos resolvem" (Brecht, 1997, p. 185).

Não há nenhum traço de melancolia em Encarnado. Comparem-se "Ciranda do Aborto" e "Uma Canção Desnaturada" (Chico Buarque), da Ópera do Malandro. Nesta, escutamos Duran e Vitória amaldiçoarem Teresinha, "a filha única, a princesinha do lar", quando ela foge "para se casar com o estelionatário, muambeiro e inimigo público no 1, Max Overseas", no Rio de Janeiro dos anos $1940^{13}$. Como outras composições da peça, que estreou em julho de 1978, a primeira camada de sentido é a da "crítica radical e desesperada dos valores sancionados pela moral burguesa". De modo específico, "Uma Canção Desnaturada" desmitifica o amor materno e o paterno: "Chega-se a um ponto em que a cor-

12 Siba e Fuloresta, "A Velha da Capa Preta". Disponível em: https://www.youtube.com/watch?v=sFS5CL6LVjE. Acesso em: 26/jul./2016.

13 Chico Buarque, Ópera do Malandro, Philips/PolyGram, 1993 [1979], texto do encarte, p. 3. 
rosão da crítica arranca não apenas a máscara, mas a pele que cobre o rosto social", nas palavras de Adélia Bezerra de Meneses (2000, pp. 73-4). A segunda camada da canção, bem como a da peça, é a da discussão do "perfil da modernização recuperadora/autoritária no Brasil”, no que estou de acordo com a análise de Homero Vizeu Araújo (2014, pp. 82-3). Resumindo ao extremo, nessa discussão o papel de Teresinha é fundamental: ela cria a Maxtertex S.A., firma que dá início à transformação da velha malandragem em um conglomerado associado ao capitalismo internacional, sobretudo ao capitalismo estadunidense. Entoada no início da peça, bem antes do final apoteótico no qual se celebra essa transformação, "Uma Canção Desnaturada" é a alegoria do desejo de retorno ao passado a fim de modificar o presente. Um desejo que figura melancólico, já que desacreditado pelos próprios "interesses materiais" que movem as personagens - interesses semelhantes, aliás, aos "da elite e da classe média adesista" no Brasil da década de 1970 (Araújo, 2014, pp. 82 e 75; Buarque, 1978). De modo coerente, no disco da Ópera do Malandro, a gravação de Chico Buarque e Marlene, com arranjo de Francis Hime, é ostensivamente melancólica.

Já "Ciranda do Aborto" nos faz ouvir o aborto em sentido literal. O foco é "a dor que uma mulher sente", o desespero dela na situação extrema do "limite entre a vida e a morte" 14 . Isto é, escutamos a recriação de uma experiência feminina, particular, ligada sobretudo a questões emocionais, e, é claro, nem por isso a experiência deixa de se vincular à esfera econômica ou de ter implicações na esfera social (Villaça, 2014). A letra começa com foco narrativo na terceira pessoa. Esse distanciamento é reforçado, logo no primeiro verso, pelo instrumento utilizado, a navalha, que sugere certa distância temporal. Entretanto, na parte B da canção ("Vem, despedaçado..."), o foco narrativo passa para a primeira pessoa. Daí até o final, a voz da canção assume o papel da personagem, e a performance de Juçara Marçal enfatiza que o gênero literário

14 Entrevista que realizei com Kiko Dinucci em 8 de junho de 2014.

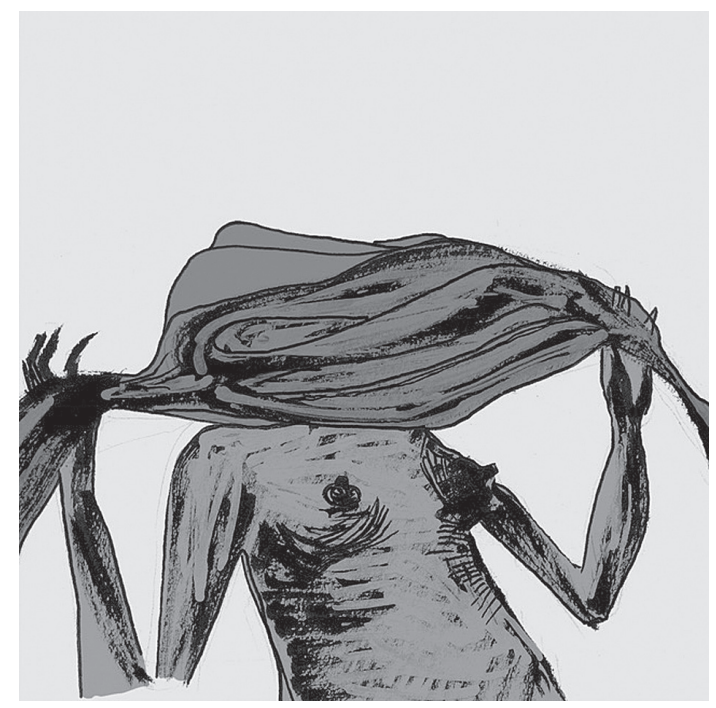

Capa do CD Encarnado,

de Jussara Marçal, 2014

predominante não é o épico, e sim, o dramático. Com isso, explicita-se o ponto de vista que organiza não só a letra, mas toda a canção: "Ciranda do Aborto" se posiciona dentro da situação e se identifica com a personagem, sem julgá-la e sem agir com condescendência - se agisse, revelaria algum suposto nível de superioridade.

Sem negar essa camada de sentido suficientemente forte e bem-sucedida, gostaria de acrescentar uma segunda interpretação. Como registrei acima, os ensaios de Encarnado se intensificaram a partir de junho e julho de 2013. Penso que, em alguma medida, a violência e a ruína sintetizadas no disco captaram e passaram a reverberar, no plano artístico, o colapso de um projeto de reforma econômica e social sustentado por um modelo econômico conservador e por arranjos políticos de curto alcance. Nessa perspectiva, é quase óbvio sublinhar que "Damião" é dedicada a Damião Ximenes Lopes e recordar que ele morreu em 4 de outubro de 1999, após três dias de internação na Casa de Repouso Guararapes, hospital psiquiátrico privado então conveniado ao Sistema Único de Saúde (Batista e Silva, 2012). Para além desse engajamento na crítica social e na batalha pela memória, a canção inspira uma luta sem tréguas, invocando Damião enquanto entidade espiritual, um encantado que "Bate até virar a cara da nação". Também é quase óbvio considerar "Não 
Tenha Ódio no Verão" como trilha sonora do rebaixamento generalizado da esfera política, ou seja, como trilha sonora da imbecilização nas redes sociais, da ferocidade caluniosa, injuriosa ou difamatória na grande imprensa, das agressões verbais e físicas nas ruas, da quebra das distinções elementares entre o público e o privado, do elogio cínico a artimanhas jurídicas, da reedição do Febeapá (Festival de Besteira que Assola o País), que, com frequência, descambaria para o Febapá (Festival de Baixaria que Assola o País): "Isso arrebenta uma nação". Entre parênteses, não custa lembrar que as relações de uma obra artística com o processo histórico imediato não a tornam, necessariamente, datada.

Se a interpretação não estiver errada, "Ciranda do Aborto", além de encarnar a dor e o desespero de uma mulher, também é a alegoria de um presente que "morreu por dentro". Falta entender o seu ponto de vista em relação à violência e à ruína. A sonoridade, a mesma que se escuta desde "Velho Amarelo" até "Presente de Casamento", indica que a canção está mergulhada na agressividade, na degradação, mas que segue construindo, sem melancolia, alguma coisa cujo fim não se sabe ainda qual será ${ }^{15}$. A construção, aliás, vem figurada no desenho de Kiko Dinucci para a capa do disco: a cantora Juçara Marçal é uma mulher negra - e não é nada irrelevante a cor da sua pele; está nua, os seios apontam para cima, mas o seu rosto permanece coberto por um pano encarnado tumultuoso; as suas unhas, todavia, estão bastante afiadas, e enquanto a mão esquerda, aberta e distensionada, já parece ter rasgado o tecido, a mão direita, curva e tensa, parece ameaçá-lo com garras.

Esse ponto de vista se torna mais compreensível com o samba "João Carranca" (Kiko Dinucci), a $12^{\text {a }}$ faixa, que encerra Encarnado. A narrativa é musicalmente bem construída, e a história tem interesse por si mesma. Relata-se o caso do personagem-título. A protagonista, no entanto, é
Guaraci. Ela é apresentada como uma profissional exemplar: tinha dedicação exclusiva ao trabalho ("Vadiava e só fazia isso"), obteve sucesso no mercado ("Foi sempre a Rainha da Boca do Lixo"), exercia o empreendedorismo ("Nunca teve cafetão/ Nem leão-de-chácara/ Apenas uma navalha"); como resultado, firmara um vínculo afetivo ("Banca e sustenta o meninão/ Que ainda cheira a leite/ E nem tem pelo na cara"). Porém, o desempenho de Guaraci, como o de qualquer um(a) de nós, tinha vida útil ("Mas o tempo passou e ela envelheceu/ Usou e gastou o corpo que Deus lhe deu"). Quando percebeu que seria descartada ("Tudo desandou depois do dia/ Em que ele resolveu causar suspiro nas mocinhas"), Guaraci fez valer a sua navalha ("A velha enciumada/ Retalhou o rosto do rapaz/E o que era belo/ Agora espanta/ E o nome dele hoje é João Carranca") - repare-se o revide, no plano simbólico, da exploração e da violência sofridas por outras mulheres, desde Bertoleza (no romance $O$ Cortiço, de Aluísio Azevedo) até Ivete (na novela "Paulinho Perna Torta", de João Antônio).

Juçara Marçal escolheu cantar o samba em "um tom bem no extremo grave", e o fonograma "vem em forma de exceção num arranjo só voz e cavaquinho" (Marçal, 2015). Ainda assim, a exceção mantém a lógica de responder às condições de produção, e a faixa, sendo inegavelmente um samba, não reproduz modelos da chamada MPB. A narradora canta com olhos realistas, como alguém que já viveu o suficiente para saber que histórias como a de Guaraci podem acontecer. Não expressa espanto, não condena, não absolve, não é condescendente. Fechando um disco que canta para Iemanjá e para Oxum, a voz que entoa "João Carranca" é a voz de uma filha da orixá Nanã Buruku, "o arquétipo das pessoas que agem com calma, benevolência, dignidade e gentileza", das pessoas que "julgam ter a eternidade à sua frente para acabar seus afazeres" (Verger, 2002, p. 241).
15 Carlos Augusto Bonifácio Leite já havia observado que Juçara Marçal, Siba e Apanhador Só, cada qual a seu modo, formulam "um prognóstico bastante negativo a respeito do estado de coisas", trabalham com "certo tom de ruína", desenvolvem uma "dicção de arestas" e buscam "ativamente uma saída razoável sem conseguir vislumbrá-la" (Leite, 2014, pp. 224-5 e 227). 


\section{BIBLIOGRAFIA}

ARAÚJO, H. V. “Um Pote Até Aqui de Mágoa: Chico Buarque e Paulo Pontes Retomam os Heróis Populares de Guarnieri e Dias Gomes", in Futuro Pifado na Literatura Brasileira. Porto Alegre, Editora da UFRGS, 2014, pp. 63-83.

BATISTA E SILVA, M. B. "O Caso Damião Ximenes e a Condenação do Brasil por Violação dos Direitos Humanos. Entrevista a M. Junges", in Revista do Instituto Humanitas Unisinos, ano XII, n 391. São Leopoldo, mai./2012. Disponível em:http://www.ihuonline.unisinos. br/index.php?option=com_content\&view=article\&id $=4407 \&$ secao $=391$. Acesso em: 2/ago./2016.

BRECHT, B. A Santa Joana dos Matadouros. Trad. R. Schwarz. Rio de Janeiro, Paz e Terra, 1997.

BUARQUE, C. Ópera do Malandro. São Paulo, Livraria Cultura Editora, 1978.

ENGELS, F. "Carta a Minna Kautsky datada de 26/11/1885", in K. Marx, F. Engels. Cultura, Arte e Literatura: Textos Escolhidos. Trad. J. P. Netto, M. M. C. Yoshida. São Paulo, Expressão Popular, 2010, pp. 65-7.

FABBRI, F. "A Theory of Musical Genres: Two Applications", in D. Horn; P. Tagg (orgs.). Popular Music Perspectives. Göteborg/Exeter, IASPM, 1981, pp. 52-81. Disponível em: http://www.tagg.org/others/ffabbri81a.html. Acesso em: 12/jul./2016.

FAGUNDES, A. "O Furacão Juçara Varre Porto Alegre”, in Noize, 8/7/2016. Disponível em: http://noize.com.br/resenha-jucara-marcal-porto-alegre/\#1. Acesso em: 27/jul./2016.

FRÓES, R. “Não Diga que Estamos Morrendo. Hoje Não!". Texto de apresentação de Encarnado, 2014. Disponível em: http://www.jucaramarcal.com/\#!encarnado/cjg9. Acesso em: 26/jul./ 2016.

KONDER, L. Os Marxistas e a Arte: Breve Estudo Histórico-Crítico de Algumas Tendências da Estética Marxista. 2a ed. São Paulo, Expressão Popular, 2013.

LEITE, C. A. B. "Sobre o Peso de Si e Maestrias: Uma Análise de Parte da Cena Atual da Canção Popular Brasileira", in Revista do Instituto de Estudos Brasileiros, n० 59. São Paulo, dez./2014, pp. 213-28. Disponível em: http://dx.doi.org/10.11606/issn.2316-901X. v0i59p213-228. Acesso em: 28/jul./2016.

MARÇAL, J. "Faixa a Faixa: Juçara Marçal Comenta Encarnado. Entrevista a R. Arruda", in O Grito!, 29/5/2015. Disponível em: http://revistaogrito.ne10.uol.com.br/page/ blog/2014/05/29/faixa-a-faixa-jucara-marcal-comenta-encarnado/. Acesso em: 27/jul./2016.

MENEZES, A. B. de Figuras do Feminino na Canção de Chico Buarque. Cotia/São Paulo, Ateliê/Boitempo, 2000.

TATIT, L. A Canção: Eficácia e Encanto. São Paulo, Atual, 1986.

VERGER, P. F. Orixás: Deuses lorubás na África e no Novo Mundo. Trad. M. A. da Nóbrega. 6a ed. Salvador, Corrupio, 2002.

VILLAÇA, T. "Ciranda do Aborto", in Polivox, mai./2014. Disponível em: http://revistapolivox. com/ciranda-do-aborto-2/. Acesso em: 28/jul./2016.

WILLIAMS, R. "Base e Superestrutura na Teoria da Cultura Marxista”, in Cultura e Materialismo. Trad. A. Glaser. São Paulo, Editora Unesp, 2011, pp. 43-68. 